\title{
Cementing Efficiency of Fly-ash in Mortar Matrix According to Binder-Water Ratio and Fly-ash Replacement Ratio
}

\author{
Cho, Hong-Bum ${ }^{1}$ Jee, Nam-Yong ${ }^{2 *}$ \\ Department of Architectural Engineering, Graduate School, Hanyang University, Seongdong-Gu, Seoul, 133-791, Korea ${ }^{1}$ \\ Department of Architectural Engineering, Hanyang University, Seongdong-Gu, Seoul, 133-791, Korea ${ }^{2}$
}

\begin{abstract}
This paper predicts the cementing efficiency of fly-ash(FA) based on mortar test considering binder-water ratio and FA replacement ratio as experimental variables. The cementing efficiency prediction model proposed by statistical analysis enables us to estimate the value according to the binder-water ratio and FA replacement ratio of matrix. When FA replacement ratio is the same, the lower the binder-water ratio, the higher the estimated cementing efficiency. There are significant differences in the values according to binder-water ratio at FA replacement ratios of $15 \%$ or less, but there are almost no differences when FA replacement ratio is more than $15 \%$. As the binder-water ratio increases, the variations in the values according to FA replacement ratio are great at FA replacement ratios of $15 \%$ or less. As the FA replacement ratios increase, the values increase for FA replacement ratios of $15 \%$ or less, but decrease for more than $15 \%$. The values range from -0.71 to 1.24 at binder-water ratio of $1.67-2.86$ and FA replacement ratio of $0-70 \%$. The RMSE of the 28-day compressive strength predicted by modified water-cement ratio is $2.2 \mathrm{MPa}$. The values can be trusted, as there is good agreement between predicted strength and experimental strength.
\end{abstract}

Keywords : fly-ash, cementing efficiency, relative strength, modified cement-water ratio, strength prediction

\section{Introduction}

Fly ash(FA) is economical and eco-friendly, as it is recycled material of an industrial by-product. Due to the dynamic characteristics and good durability of FA concrete, FA has gradually been used in the concrete industry. To minimize the trial mixes of concrete containing FA, improve the accuracy and efficiency of design of mix proportion $[1,2]$ and predict compressive strength[3,4,5], it is important to understand the cementing efficiency of FA. To predict the cementing efficiency of FA,

Received : October 14, 2011

Revision received : February 3, 2012

Accepted : February 17, 2012

* Corresponding author: Jee, Nam-Yong

[Tel: 82-2-2220-0302, E-mail: nyjee@hanyang.ac.kr]

(c)2012 The Korea Institute of Building Construction, All rights reserved.
Smith[6], considering differences in strength development according to the pozzolan reaction, expressed the cementing efficiency of FA using $k$ to convert mass of $\mathrm{FA}(F)$ into equivalent mass of $\mathrm{OPC}(k F)$. The water-binder ratio $(W /(C+F))$ can be converted into modified water-cement ratio $(W /(C+k F))$ according to the cementing efficiency of FA[7]. The compressive strength is generally used to determine the cementing efficiency, and the following are the concepts that can be utilized: the strength activity index[8], the concept of relative strength[9] which expresses the ratio of compressive strength of pozzolan concrete to that of OPC concrete, and the overall efficiency[10] which combines the general efficiency incorporating the influence of age with the percentage efficiency according to the pozzolan replacement ratio. 
Cho[11] suggested a prediction model for the cementing efficiency of FA through a statistical analysis using the concept of Bolomey' $\mathrm{s}$ strength equation and relative strength $(R s)$. Since the prediction model enables researchers to calculate the cementing efficiency of FA using only concrete mixture rather than experimental test results, it can be utilized in the mix design and quality control of FA concrete. However, the model was derived based on the ready-mixed concrete data, rather than by controlling the mixture factors that can affect the cementing efficiency under the same experimental conditions. For this reason, it should be verified through an experiment designed to use the variables of the suggested prediction model as experimental factors.

The cementing efficiency of FA in the prediction model is determined by factors other than aggregate in the mixture. This research aims to present a prediction model for cementing efficiency of FA, and estimate cementing efficiency $\left(k_{p}\right)$ based on a mortar experiment using binder-water ratio and FA replacement ratio as experimental variables.

\section{Prediction model for cementing efficiency}

Cementing efficiency is affected by the physical and chemical characteristics of the binder, mix proportion, age, and curing condition. For this reason, it is almost impossible to suggest a prediction model for cementing efficiency that can consider all these factors. The various prediction models were suggested by considering binder type[8,9] and fineness[4], pozzolan replacement ratio[3,4,8,9], and age[4,10]. These were used for the design of mix proportion[1,2] and strength prediction[3,4,5]. In particular, it is revealed that as more FA is used, the cementing efficiency of FA gradually becomes lower, within the range between
0.2 and $1.3[2,3,4,10]$. However, the value was reflected only by the FA replacement ratio of various mixture factors, so to reflect the optimal mixture in terms of strength and economic feasibility, we suggest an equation for predicting cementing efficiency of FA based on the contents of matrix materials and $R s$, as shown in Eq. (1) from a previous study[11].

$$
k=\left(\frac{C+F-0.5 W}{F}\right) \times(R s-1)+1
$$

where, $R s$ is relative strength(ratio of compressive strength of FA mixture to that of $\mathrm{OPC}$ mixture); $C, F$, and $W$ are $\mathrm{OPC}, \mathrm{FA}$, and water content in the mixture, respectively; $k$ is the cementing efficiency of FA.

Since Eq. (1) is based on Bolomey' s strength equation, which is expressed as a linear equation for the compressive strength based on cement-water ratio, binder-water ratio is used instead of water-binder ratio. The Rs in Eq. (1) is an experimental value. To express the cementing efficiency of FA with a function of the mixture composition, a linear function of binder-water ratio and FA replacement ratio was suggested as shown in Eq. (2). That is, the prediction model for cementing efficiency of FA can be expressed as a function of the mixture by replacing $R s$ in Eq. (1) with Eq. (2), the estimation equation for $R s$. Therefore, the accuracy of Eq. (2) is an important factor in the reliability of the estimated cementing efficiency of $\mathrm{FA}\left(k_{p}\right)$.

$$
R s=c(C+F) / W+d F /(C+F)+e---(2)
$$

where, $(C+F) / W$ is the binder-water ratio of FA mixture; $F /(C+F)$ is the FA replacement ratio of FA mixture; $c, d$, and $e$ are the experimental constants. 
If the concrete contains FA, $k_{p}$ could be determined only by the factors in the matrix such as unit contents of cement, FA, and water, binder-water ratio, and FA replacement ratio, using Eqs. (1) and (2). The $k_{p}$ was verified by comparing predicted strength using $\left(C+k_{p} F\right) / W$ and experimental strength and analyzing the standard error of estimation(Root Mean Squares Error, RMSE).

\section{Experimental plan and results}

Experimental variables are binder-water ratio and FA replacement ratio, and the other conditions of the experiment including factors related to the mixture were controlled equally.

\subsection{Materials}

As the binder for the mortar experiment, OPC of Company $\mathrm{H}$ and 2 kinds of FA(ASTM Class F) from Boryeong were used. The properties of the binder are indicated in Table 1. Standard sand prescribed in KS L ISO 679 from Jumunjin was used as a fine aggregate.

Table 1. Properties of binder

\begin{tabular}{ccccccc}
\hline Binder & Density & Blaine & $\begin{array}{c}\text { Ignition } \\
\text { Loss } \\
\left(\mathrm{g} / \mathrm{cm}^{3}\right)\end{array}$ & $\begin{array}{c}\text { Flow } \\
\left(\mathrm{cm}^{2} / \mathrm{g}\right)\end{array}$ & $\begin{array}{c}\text { Compressive strength } \\
(\%)\end{array}$ & $\begin{array}{c}\text { (MPa) of OPC } \\
\text { or }\end{array}$ \\
\cline { 6 - 7 } & & & & & Activity index $(\%) \star *$ & of $\mathrm{FA}$ \\
\hline OPC & 3.15 & 3348 & 1.77 & - & 29.0 & 40.9 \\
FA & 2.19 & 3540 & 3.50 & 100 & 71 & 90 \\
\hline
\end{tabular}

* Flow ratio is the flow percentage of FA mortar to control mortar.

** Activity index is the ratio of compressive strength of FA mortar to control mortar.

For FA mortar, OPC and FA are mixed in the mass ratio of $3: 1$.

To evaluate the strength activity index(AI), which has a close relationship with the pozzolan reaction of FA, the mass ratio of binder and standard sand was $1: 3$ with water-binder ratio of 0.5 according to KS L 5405, and the specimen was manufactured and cured according to KS L ISO 679. The flow ratio of FA was measured as 100\%, while the 7-day AI and the 28-day AI were measured as $71 \%$ and $90 \%$, respectively.

\subsection{Mix proportions}

Considering the general range of concrete with specified compressive strength lower than $40 \mathrm{MPa}$, the binder-water ratio was set to three different levels: 1.67, 2.06, and 2.86. FA replacement ratio was set to nine different levels: 0, 5, 10, 15, 20, $25,30,50,70 \%$ considering the generally applicable range of FA replacement ratio lower than $25 \%$ and the special range required to replace a high volume of $\mathrm{FA}[12]$ in order to reduce heat of hydration and secure high durability. Therefore, a total of 27 mortars were mixed by changing binder-water ratio and FA replacement ratio in order to understand the cementing efficiency of FA, as shown in Table 2.

An equal volume of binder and aggregate was put into the mortars. The mass ratio of binder and aggregate was 1:2.45 according to KS L 5105. To effectively understand the influence of water-binder ratio, the volume of $\mathrm{OPC}$ and $\mathrm{FA}$ was mixed to be equal in the FA replacement ratio. The binder-water ratio was adjusted according to the unit quantity, and FA was replaced for OPC in the control group mortar by weight.

\subsection{Specimen preparation and curing}

After mixing each mortar according to KS L ISO 679, the flow test was carried out according to KS L 5111, and specimens were manufactured using the cubic mould $(50 \times 50 \times 50 \mathrm{~mm})$ according to $\mathrm{KS} \mathrm{L}$ 5105. After the formation, the moulds were kept in a constant temperature and humidity chamber at $21^{\circ} \mathrm{C}$ and relative humidity of $95 \%$ for 24 hours. 
Then, the moulds were detached and the specimens cured in a water tank at $23 \pm 2^{\circ} \mathrm{C}$ until the day of testing.

\subsection{Test results}

Table 2 indicates the flow, compressive strength, and $R s$ of each mortar. The difference between the flow of mortar with FA and that of the control group was shown to be lower than $10 \%$ up to the FA replacement ratio of 50\%, which means there was no significant change in the flow according to FA replacement. The $R s$ was shown to be highest (more than 1) at an FA replacement ratio of $15 \%$. When FA replacement ratio was lower than $15 \%$, $R s$ increased in a manner proportional to the FA replacement ratio. However, when FA replacement ratio was higher than $15 \%, R s$ increased in a manner inversely proportional to the FA replacement ratio.

\section{Prediction of the cementing efficiency of FA}

\subsection{Estimation equation for Rs}

It is necessary to present a model to accurately estimate $R s$ using the mix proportions in order to propose a prediction model for cementing efficiency of FA using only the mix proportions. Therefore, to present a prediction model for $R s$, a regression analysis on experimental factors was carried out using SPSS1), predictive analytics software.

\subsubsection{FA replacement ratio}

At 28 days $R s$ according to FA replacement ratio was analyzed to be a quadratic function of FA replacement ratio as illustrated in Figure 1. The RMSE of estimated relative strength was 0.065. However, this equation cannot explain the increase in $R s$ as the binder-water ratio decreased and the

1) $\mathrm{IBM} \circledast \mathrm{SPSS} \circledast$ Ver. 18
Table 2. Mix proportions and test results

\begin{tabular}{|c|c|c|c|c|}
\hline \multicolumn{2}{|c|}{ Mix proportions } & \multirow{2}{*}{$\begin{array}{l}\text { Mortar } \\
\text { flow } \\
(\mathrm{mm})\end{array}$} & \multirow{2}{*}{$\begin{array}{c}\text { 28-day } \\
\text { compressive strength } \\
(\mathrm{MPa})\end{array}$} & \multirow{2}{*}{$R s$} \\
\hline$B / W$ & $\mathrm{~F} / \mathrm{B}$ & & & \\
\hline \multirow[t]{9}{*}{2.86} & 0 & 105 & 39.5 & - \\
\hline & 0.05 & 113 & 34.5 & 0.874 \\
\hline & 0.10 & 109 & 36.1 & 0.915 \\
\hline & 0.15 & 106 & 39.5 & 1.000 \\
\hline & 0.20 & 107 & 38.6 & 0.978 \\
\hline & 0.25 & 110 & 34.9 & 0.885 \\
\hline & 0.30 & 109 & 31.5 & 0.797 \\
\hline & 0.50 & 109 & 28.0 & 0.709 \\
\hline & 0.70 & 110 & 13.4 & 0.340 \\
\hline \multirow[t]{9}{*}{2.06} & 0 & 138 & 37.4 & - \\
\hline & 0.05 & 137 & 36.3 & 0.970 \\
\hline & 0.10 & 132 & 36.8 & 0.983 \\
\hline & 0.15 & 136 & 38.8 & 1.037 \\
\hline & 0.20 & 136 & 35.1 & 0.937 \\
\hline & 0.25 & 141 & 33.4 & 0.892 \\
\hline & 0.30 & 141 & 32.4 & 0.866 \\
\hline & 0.50 & 145 & 21.1 & 0.563 \\
\hline & 0.70 & 174 & 6.4 & 0.172 \\
\hline \multirow[t]{9}{*}{1.67} & 0 & 175 & 33.7 & - \\
\hline & 0.05 & 175 & 33.6 & 0.996 \\
\hline & 0.10 & 177 & 34.0 & 1.008 \\
\hline & 0.15 & 186 & 34.5 & 1.022 \\
\hline & 0.20 & 188 & 32.2 & 0.954 \\
\hline & 0.25 & 192 & 30.9 & 0.918 \\
\hline & 0.30 & 191 & 26.9 & 0.797 \\
\hline & 0.50 & 190 & 15.1 & 0.448 \\
\hline & 0.70 & 218 & 5.3 & 0.157 \\
\hline
\end{tabular}

$\mathrm{B} / \mathrm{W}=$ binder-water ratio; $\mathrm{F} / \mathrm{B}=\mathrm{FA}$ replacement ratio; $\mathrm{Rs}=$ the ratio of strength of FA mortar to that of control mortar The $\mathrm{B} / \mathrm{W}$ of $2.86,2.06$, and 1.67 are equal to $\mathrm{W} / \mathrm{B}$ of 0.35 , 0.485 , and 0.60 , respectively.

The binder content of all mixtures is $760 \mathrm{~g}$.

FA replacement ratio increased in the FA replacement ratio of $15 \%$ or less. Thus, an estimation equation for $R s$ that reflects this phenomenon is needed in order to accurately explain the strength development.

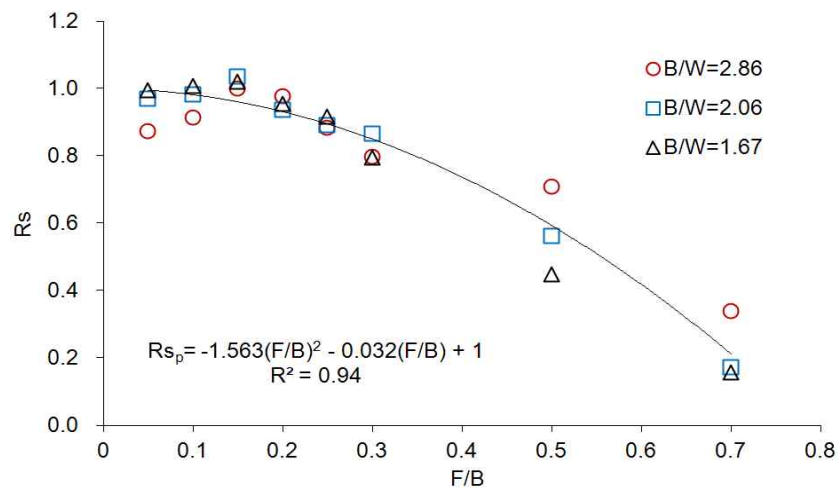

Figure 1. Rs according to FA replacement ratio by binder-water ratio 
Table 3. Regression analysis results on Rs with binder-water ratio and $F A$ replacement ratio $(R s=c(B / W)+d(F / B)+e)$

\begin{tabular}{|c|c|c|c|c|c|c|c|c|}
\hline \multirow{2}{*}{$\begin{array}{l}\text { FA replacement ratio } \\
\qquad(\mathrm{F} / \mathrm{B})\end{array}$} & \multicolumn{2}{|c|}{ Regression coefficient } & \multicolumn{2}{|c|}{$\begin{array}{l}\text { Standardized } \\
\text { regression coefficient }\end{array}$} & \multirow{2}{*}{$\frac{\text { Constant }}{\mathrm{e}}$} & \multirow[t]{2}{*}{$\mathrm{R}$} & \multirow[t]{2}{*}{$R^{2}$} & \multirow[t]{2}{*}{ RMSE } \\
\hline & c & $d$ & $c^{\prime}$ & $d^{\prime}$ & & & & \\
\hline $0<\mathrm{F} / \mathrm{B} \leq 0.15$ & -0.069 & 0.729 & -0.691 & 0.603 & 1.057 & 0.917 & 0.841 & 0.024 \\
\hline $0.15<F / B \leq 0.7$ & - & -1.448 & - & -0.971 & 1.259 & 0.971 & 0.943 & 0.071 \\
\hline
\end{tabular}

$\mathrm{c}$ and $\mathrm{d}$ are regression coefficients of binder-water ratio and FA replacement ratio, respectively.

Each $\mathrm{p}$-value of independent variables is lower than 0.05 .

$\mathrm{R}=$ correlation coefficient, $\mathrm{R}^{2}=$ determination coefficient, $\mathrm{RMSE}=$ standard error of estimation

\subsubsection{Binder-water ratio and FA replacement ratio}

Figure 1 shows that $R s$ is highest at a FA replacement ratio of $15 \%$, and to express a linear function of binder-water ratio and FA replacement ratio as Eq. (2), the results were divided by FA replacement ratio into two groups: one when FA replacement ratio was $15 \%$ or less and the other when FA replacement ratio was higher than $15 \%$. Multiple linear regression analysis was performed on each group, and Table 3 provides the results of regression analysis. In particular, at an FA replacement ratio of $15 \%$ or less, the RMSE of the linear function is lower than that of the quadratic function in Figure 1, so $R s$ is more accurately estimated when using the linear function.

When lower than $15 \%$, as the binder-water ratio decreased and FA replacement ratio increased, $R s$ went up, which is identical to the result of a previous study[11] based on the concrete data. However, when FA replacement ratio is higher than $15 \%$, the regression coefficient of binder-water ratio was insignificant ( $p>0.05$ ), and a linear function of FA replacement ratio was derived. The estimation equation for $R s$ in Table 3 had a higher coefficient of determination $\left(\mathrm{R}^{2}\right)$ and a lower RMSE than the equation presented by Cho[11] using the concrete data. Therefore, the influence of binder-water ratio and FA replacement ratio on the cementing efficiency of FA can be understood more clearly.

At the FA replacement ratio of $15 \%$, the strength development according to the FA replacement ratio was reversed. Because the volume of binder was fixed at a certain level, the additional OPC was not supplied with the increase of FA replacement ratio. Therefore, calcium hydroxide $\left(\mathrm{Ca}(\mathrm{OH})_{2}, \mathrm{CH}\right)$ was not yielded continually. That is, when FA replacement ratio was lower than $15 \%$, $\mathrm{CH}$ that was necessary for the pozzolan reaction was supplied, but when FA replacement ratio was higher than $15 \%, \mathrm{CH}$ was insufficient, and the pozzolan reaction decreased accordingly.

When lower than $15 \%$, the absolute value of the standardized regression coefficient of binder-water ratio was higher than that of the FA replacement ratio; thus, not only the influence of FA replacement ratio but also binder-water ratio for $R s$ should be considered. However, when FA replacement ratio is higher than 15\%, the absolute value of the standardized regression coefficient of FA replacement ratio was shown to be close to 1 , which means $R s$ was absolutely affected by FA replacement ratio.

\subsection{Prediction model for cementing efficiency of FA}

A prediction model for cementing efficiency of FA was drawn by substituting the estimation equation for $R s$ with the regression coefficient shown in Table 3 for Eq. (1). The prediction model for cementing efficiency of FA can be expressed as

2) Standardized regression coefficients of independent variables indicate the relative impact on the dependent variable, and range from -1 to 1 . The larger absolute value is, the greater influence. 
Eqs. (3) and (4) according to FA replacement ratio.

$$
\begin{aligned}
& k_{p 1}=-0.069 \frac{y}{x}+0.092 \frac{1}{x}-0.365 \frac{1}{y}-0.029 \frac{1}{x y}+1.729-(3) \\
& k_{p 2}=0.259 \frac{1}{x}+0.724 \frac{1}{y}-0.130 \frac{1}{x y}-0.448------(4)
\end{aligned}
$$

where, $k_{p 1}$ and $k_{p 2}$ are estimated cementing efficiency when FA replacement ratio is at $15 \%$ or less and at higher than $15 \%$, respectively; $x$ is $\mathrm{FA}$ replacement ratio(F/B); $y$ is binder-water ratio $(\mathrm{B} / \mathrm{W})$.

Figure 2 illustrates the estimated cementing efficiency $\left(k_{p}\right)$ of FA calculated using Eqs. (3) and (4). Eq. (3) was used when the binder-water ratio was between 1.67 and 2.86, and FA replacement ratio was $15 \%$ or less, while Eq. (4) was used when FA replacement ratio was higher than $15 \%$. The $k_{p}$ ranged from -0.71 to 1.24 when calculated using the two equations.

Eqs. (3) and (4) can be utilized for designing mix proportion, because users can understand the range of FA replacement ratio(16 17\%, 12 18\%, and 8 $18 \%$ at $\mathrm{B} / \mathrm{W}$ of $2.86,2.06$, and 1.67 , respectively) at which $k_{p}$ is higher than 1 , and the highest FA replacement ratio at which the strength of the FA mixture is higher than that of control group, as illustrated in Figure 2.

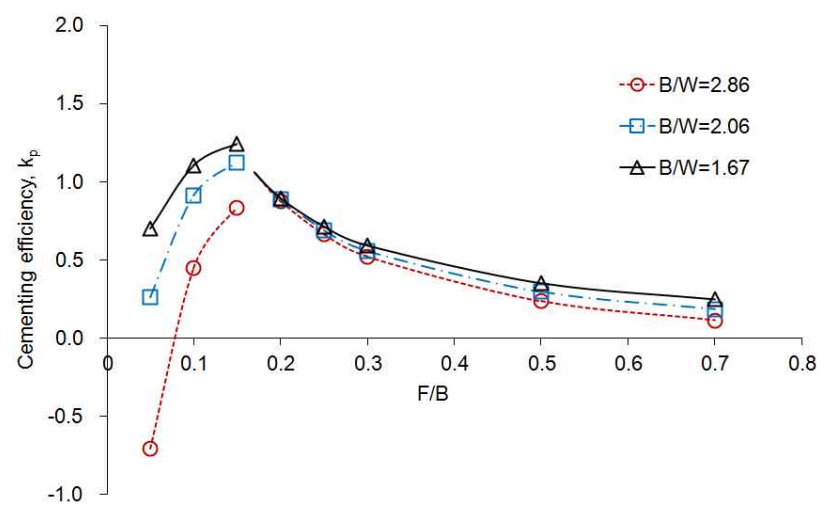

Figure 2. $k_{p}$ determined by Eqs. (3) and (4) according to FA replacement ratio and binder-water ratio

The higher $\mathrm{B} / \mathrm{W}$ was, the lower $k_{p}$ became at the same $\mathrm{F} / \mathrm{B}$, because the decrease in $\mathrm{CH}$ from $\mathrm{OPC}$ caused the pozzolan reaction to be reduced[14]. It is difficult to expect a higher strength than the control group through FA replacement at 28 days because $k_{p}$ is less than 1 at all FA replacement ratios when $\mathrm{B} / \mathrm{W}$ is higher than 2.86 . In particular, $k_{p}$ was shown to be negative at $\mathrm{B} / \mathrm{W}$ of 2.86 and $\mathrm{F} / \mathrm{B}$ of $5 \%$. That is, when FA replacement ratio is more than $7 \%$, the effect on strength development of FA can be expected. A negative value is shown when $R s$ is less than 1 in Eq. (1). The $R s$ was shown to be less than 1, when FA replacement ratio was low and binder-water ratio was high[11]. The negative value turned positive as pozzolan reaction proceeded over time.

When FA replacement ratio was $15 \%$ or less, the higher $\mathrm{B} / \mathrm{W}$, the more variation of $k_{p}$ according to F/B. However, when FA replacement ratio was higher than 15\%, there was no significant difference found, and $k_{p}$ gradually decreased as F/B increased.

\subsection{Verification of the prediction model}

The experimental cementing efficiency $\left(k_{e}\right)$ calculated using Eq. (1) with Rs based on the test results and the predicted cementing efficiency $\left(k_{p}\right)$ calculated using Eqs. (3) and (4) were compared. The reliability of the prediction model was evaluated by RMSE of predicted strength based on the cementing efficiency of each.

\subsubsection{Strength prediction by $\left(\mathrm{C}+\mathrm{k}_{\mathrm{e}} \mathrm{F}\right) / \mathrm{W}$}

The $R s$ in Table 2 was applied to Eq. (1) to calculate $k_{e}$. The correlations between $\left(C+k_{e} F\right) / W$ that reflects the $k_{e}$ between -1.07 and 1.19 and 28-day compressive $\operatorname{strength}\left(f_{(28)}\right)$ are shown in Figure 3. The $f_{(28)}$ is expressed as the linear function of $\left(C+k_{e} F\right) / W, f_{(28)}=a\left\{\left(C+k_{e} F\right) / W-0.5\right\}$, RMSE was $0.24 \mathrm{MPa}$ and the coefficient of determination was close 
to 1. The coefficient a can be expressed as the function of water content $\left[a=0.064 \mathrm{~W}, \mathrm{R}^{2}=0.99\right]$. This value is an index showing water sensitivity of compressive strength, which can be affected by age, strength, and cement type[13]. As the binder-water ratio gradually became lower, the yield of $\mathrm{CH}$ increased[14]. Therefore, the cementing efficiency of FA increased because the pozzolan reaction that formed the calcium silicate hydrate(CSH) from $\mathrm{CH}$ became more active with FA replacement, so that the coefficient $a$ increased.

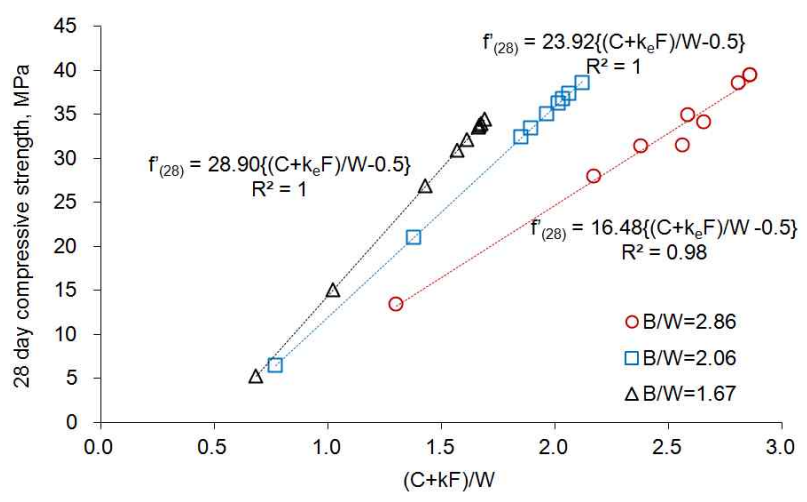

Figure 3. Relationship between modified cement-water ratio and 28-day compressive strength based on mortar test

The $k_{e}$ was derived based on the FA concrete data of Han[15] and Mathews[16], and Figure 4 shows the correlations between $\left(C+k_{e} F\right) / W$ and compressive strength. The $k_{e}$ calculated using data of Han was $0.19 \sim 1.43$ within the range of $\mathrm{B} / \mathrm{W}$ of $1.67 \sim 3.70$ and $\mathrm{F} / \mathrm{B}$ of $0 \sim 30 \%$, while $k_{e}$ calculated using data of Mathews was 0.69 1.55 within the range of $\mathrm{B} / \mathrm{W}$ of $1.75 \sim 2.33$ and $\mathrm{F} / \mathrm{B}$ of $0 \sim 20 \%$.

Figure 5 (a) shows the comparison between experimental strength and predicted strength by $\left(C+k_{e} F\right) / W$. The RMSE was $1 \mathrm{MPa}$, and the compressive strength is predicted within the error range of $\pm 4 \%$. Figure 5 (b) is the results of a comparison between experimental strength and predicted strength by $(C+F) / W$ without considering $k_{e}$, and the RMSE was $4.4 \mathrm{MPa}$.

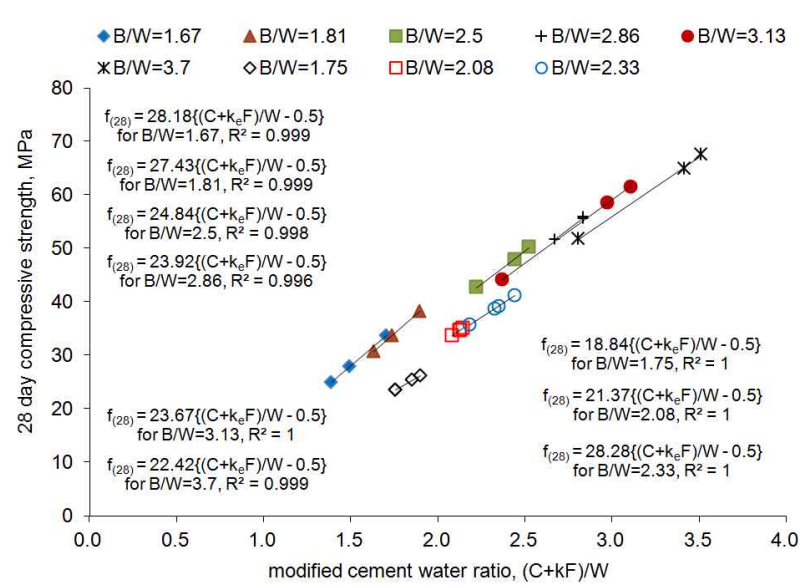

Figure 4. Relationship between modified cement-water ratio and 28-day compressive strength based on FA concrete data of ref. [15] \& [16]

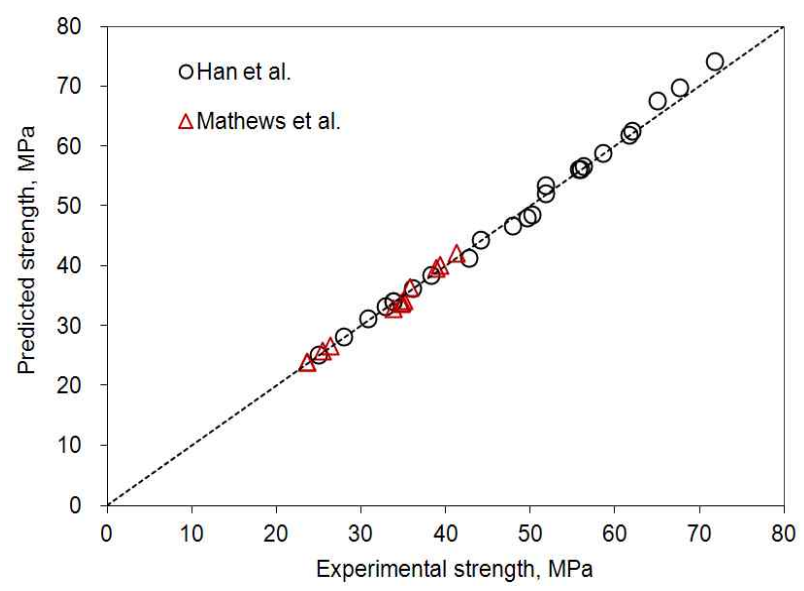

(a) Strength prediction by $\left(\mathrm{C}+\mathrm{k}_{\mathrm{e}} \mathrm{F}\right) / \mathrm{W}$

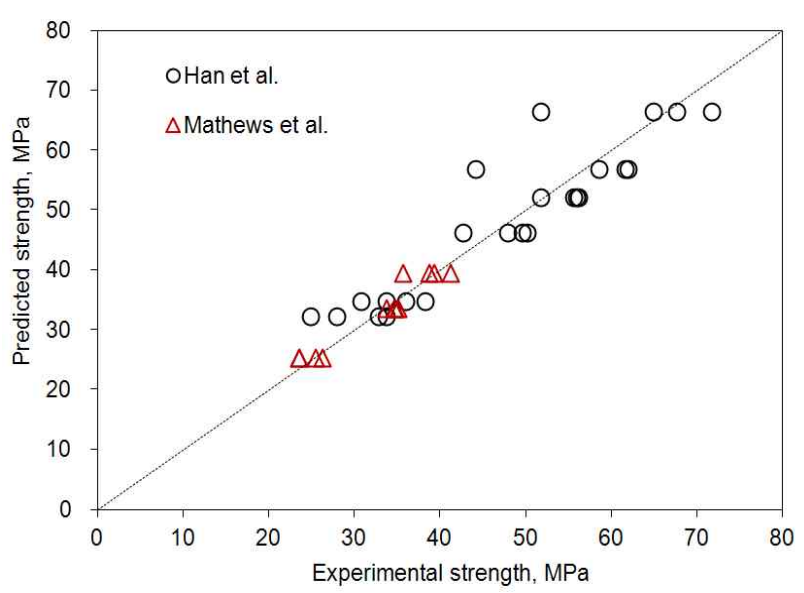

(b) Strength prediction by $(\mathrm{C}+\mathrm{F}) / \mathrm{W}$

Figure 5. Comparison between experimental strength and strength predicted by modified cement water ratio and binder-water ratio in ref. 〔15] \& [16 
The $R s$ was drawn based on the experimental results of mortar and concrete, and then applied to Eq. (1) to obtain $k_{e}$. The RMSE of the predicted strength obtained by $\left(C+k_{e} F\right) / W$ was less than 1 $\mathrm{MPa}$, which is very similar to the experimental strength. Therefore, Eq. (1), the ground equation for the prediction model, is reliable and thus applicable to mortar and concrete as well.

\subsubsection{Strength prediction by $\left(\mathrm{C}+\mathrm{k}_{\mathrm{p}} \mathrm{F}\right) / \mathrm{W}$}

The 28-day compressive strength was predicted using $f_{(28)}=a\left\{\left(C+k_{p} F\right) / W-0.5\right\}$ where the $k_{p}$ obtained from Eqs. (3) and (4) is applied. Here, the $a$ value was calculated by the function of water content mentioned earlier. Figure 6 is derived by comparing predicted strength and experimental strength, and RMSE was $2.2 \mathrm{MPa}$.

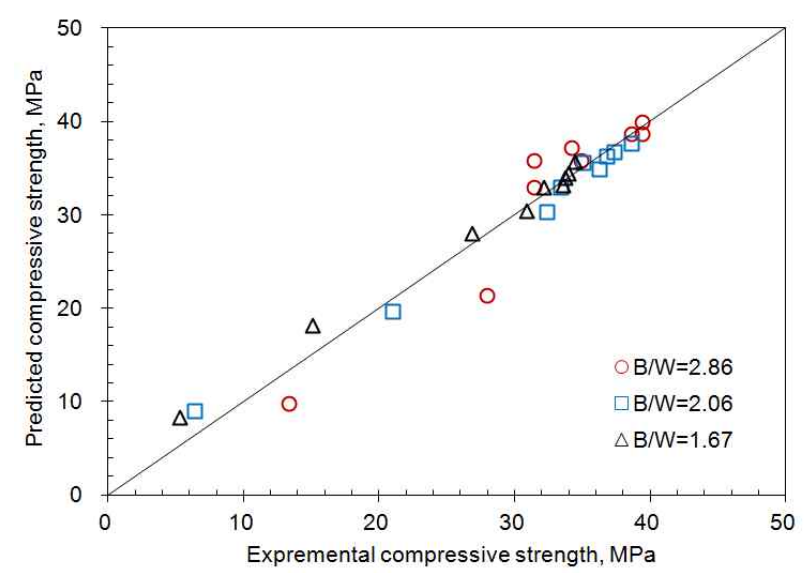

Figure 6. Comparision between experimental strength and strength predicted by $\left(\mathrm{C}+\mathrm{k}_{\mathrm{p}} \mathrm{F}\right) / \mathrm{W}$

From the test results, it was found that the maximum difference between $k_{e}$ and $k_{p}$ was 0.36 , and RMSE was 0.15. The difference was not significant, so the predicted strength obtained by $\left(C+k_{p} F\right) / W$ was very similar to the experimental strength. Therefore, the prediction model for cementing efficiency of FA, Eqs. (3) and (4) using $\mathrm{B} / \mathrm{W}$ and $\mathrm{F} / \mathrm{B}$, is believed to have high reliability.

\section{Conclusions}

A prediction model for 28-day cementing efficiency of FA and estimated cementing efficiency $\left(k_{p}\right)$ was presented, where the binder-water ratio and FA replacement ratio were considered. In addition, the estimated strength obtained using the modified cement-water ratio $\left(\left(C+k_{p} F\right) / W\right)$ was evaluated to determine the reliability and applicability of the prediction model for cementing efficiency of FA.

In the range of binder-water ratio of 1.67 2.86 and FA replacement ratio of $0 \sim 70 \%, k_{p}$ obtained from the prediction model ranged from -0.71 to 1.24. The lower the binder-water ratio, the higher $k_{p}$ at the same FA replacement ratio. Up to an FA replacement ratio of $15 \%$, as the binder-water ratio went up, the increase of $k_{p}$ according to FA replacement ratio was also shown to be high. However, In FA replacement ratio of more than $15 \%$, there were no significant differences in $k_{p}$ according to binder-water ratio, but $k_{p}$ gradually decreased as FA replacement ratio went up.

This is conducive to understanding the range of FA replacement ratio $(16 \sim 17 \%$ at $\mathrm{B} / \mathrm{W}$ of $2.86,12$ $\sim 18 \%$ at $\mathrm{B} / \mathrm{W}$ of 2.06 and $8 \sim 18 \%$ at $\mathrm{B} / \mathrm{W}$ of 1.67 ) at which $k_{p}$ is higher than 1 when calculated using the prediction model, which can be utilized for the mix design.

The standard error of the estimated 28-day compressive strength using $f_{(28)}=a\left\{\left(C+k_{p} F\right) / W-0.5\right\}$ was $2.2 \mathrm{MPa}$, which means that the predicted strength is in good agreement with the experimental strength. Therefore, the prediction model for cementing efficiency of FA and $k_{p}$ can be significant and reliable.

\section{References}

1. Bharatkumar BH, Narayanan R, Raghuprasad BK Ramachandramurthy 
DS. Mix proportioning of high performance concrete. Cement and Concrete Composites. 2001 Feb;23(1):71-80.

2. Oner A, Akyuz S, Yildiz R. An experimental study on strength development of concrete containing fly ash and optimum usage of fly ash in concrete. Cement and Concrete Research. 2005 Jun;35(6):1165-71.

3. Rajamane NP, Peter JA, Ambily PS. Prediction of compressive strength of concrete with fly ash as sand replacement material. Cement and Concrete Composites. 2007 Mar;29(3):218-23.

4. Hwang K, Noguchi T, Tomosawa F. Prediction model of compressive strength development of fly-ash concrete. Cement and Concrete Research. 2004 Dec;34(12):2269-76.

5. Hedegaard SE, Hansen TC. Modified Water Cement Ratio Law for Compressive Strength of Fly-Ash Concretes. Materials and Structures. 1992 Jun;25(5):273-83.

6. Smith IA. The design of fly ash concretes. ICE Proceedings. 1967 Apr;36(4):769-90.

7. Neville AM. Neville on Concrete - An Examination of Issues in Concrete Practice. 2nd ed. London: BOOKSURGE LLC; 2006. Chapter2.5, How Useful is the Water-cement Ratio; $p$. $2-50$.

8. Papadakis VG, Antiohos S, Tsimas S. Supplementary cementing materials in concrete-Part II: A fundamental estimation of the efficiency factor. Cement and Concrete Research. 2002 Oct;32(10):1533-8.

9. Wong HS, Razak HA. Efficiency of calcined kaolin and silica fume as cement replacement material for strength performance. Cement and Concrete Research. 2005 Apr;35(4):696-702.

10. Babu KG, Rao GSN. Efficiency of fly ash in concrete with age. Cement and Concrete Research. 1996 Mar;26(3):465-74.

11. Cho HB, Jee NY. Prediction Model for Cementing Efficiency of Fly Ash Concrete by Statistical Analyses. Advanced Materials Research. 2011 Mar;250-253:1293-96.

12. Mehta PK. High-performance high-volume fly ash concrete for sustainable development. In: Kejin Wang, editor. Proceedings of the international workshop on sustainable development and concrete technology; 2004 May 20-21; Beijing (China). Iowa (IA): Iowa State University Publication; 2004. p. 3-14.

13. Popovics S. Strength and related properties of concrete: a quantitative approach. 1st ed. New York: John Wiley \& Sons; 1998. Chapter 5.7, Discussion of Abrams' Formula for compressive strength; p. 335-43.
14. Hanehara S, Tomosawa F, Kobayakawa M, Hwang KR. Effects of water/powder ratio, mixing ratio of fly ash, and curing temperature on pozzolanic reaction of fly ash in cement paste. Cement and Concrete Research. 2001 Jan;31(1):31-9.

15. Han SH, Kim JK, Park YD. Prediction of compressive strength of fly ash concrete by new apparent activation energy function. Cement and Concrete Research. 2003 Jul;33(7):965-71.

16. Mathews MS, Somayaji S, Ambedkar GSB. Effects of Fly Ash on Strength and Durability of Hydraulic Structures with Various Grades of Cement and Concrete. In: Malhotra VM. editor. Seventh CANMET /ACI International Conference on Fly ash, Silica Fume, Slag, and Natural Pozzolans in Concrete; 2001 July 22-27; Madras (India). Farmington Hills (M): ACI; 2001. p. 127-46. 